\title{
A VACINAÇÃO OBRIGATÓRIA E OS DIREITOS FUNDAMENTAIS: UMA ANÁLISE DO ORDENAMENTO JURÍDICO BRASILEIRO E DO ENTENDIMENTO DO SUPREMO TRIBUNAL FEDERAL
}

\author{
THE MANDATORY VACCINATION AND FUNDAMENTAL \\ RIGHTS: AN ANALYSIS OF THE BRAZILIAN LEGAL ORDER \\ AND THE UNDERSTANDING OF THE SUPREME FEDERAL \\ COURT
}

\author{
Eduardo Domingues Rezende ${ }^{1}$ \\ Américo Bedê Freire Junior ${ }^{1}$
}

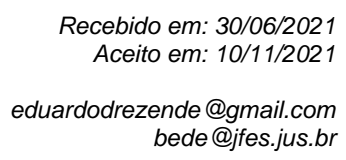
bede@jfes.jus.br
Resumo: O presente artigo se propõe a analisar a compatibilidade da exigência da vacinação obrigatória pela Lei Federal n.ำ13.979/2020 com o paradigma do Estado Democrático de Direito. Para tanto, perpassaremos pelo contexto fático que levaram a essa exigência, que teve início no século XIX, se intensificou com a pandemia da varíola em 1904 no Rio de Janeiro/RJ e passou a ser tema de debate com o advento da pandemia da Covid-19. Diante dessa perspectiva, analisar-se-á a decisão proferida pelo Supremo Tribunal Federal nas ações diretas de inconstitucionalidade $n .-6.586$ e 6.587, que colocou em debate a (in)constitucionalidade da obrigatoriedade da vacinação. Assim, utilizando como metodologia a pesquisa bibliográfica, sob uma abordagem dialética, concluiremos, sem esgotar os estudos sobre o tema, que é compatível com o paradigma do Estado Democrático de Direito a aplicação de medidas coercitivas indiretas de forma a garantir a obrigação da vacinação contra Covid-19, uma vez significa a própria promoção do direito fundamental à saúde e, via de consequência, da própria dignidade humana. Sugere-se, ainda, a adoção de medidas incentivadoras à vacinação, de forma a corroborar ainda mais com vacinação em massa e promover, inclusive, políticas públicas para amenizar as consequências negativas da pandemia no mercado financeiro.

Palavras-chave: Covid-19. Estado Democrático de Direito. Liberdade Individual. Saúde Pública. Vacinação obrigatória.

\begin{abstract}
This article proposes to analyze the compatibility of the mandatory vaccination requirement by Federal Law No. 13,979 / 2020 with the Democratic Rule of Law paradigm. To do so, we will go through the factual context that led to this demand, which began in the 19th century, intensified with the smallpox pandemic in 1904 in Rio de Janeiro / RJ and became the subject of debate with the advent of the Covidean pandemic. 19. In light of this perspective, the decision handed down by the Supreme Federal Court in direct actions of unconstitutionality no. 6,586 and 6,587 will be analyzed, which put into question the (un) constitutionality of mandatory vaccination. Thus, using bibliographic research as a methodology, under a dialectical approach, we will conclude, without exhausting the studies on the theme, that it is compatible with the paradigm of the Democratic State of Law the application of indirect coercive measures in order to guarantee the obligation of vaccination against Covid-19, once means the promotion of the fundamental right to health and, consequently, of human dignity. It is also suggested the adoption of measures to encourage vaccination, in order to further corroborate mass vaccination and even promote public policies to alleviate the negative consequences of the pandemic in the financial market.
\end{abstract}

Keywords: Covid-19. Democratic state. Individual freedom. Public health. Mandatory vaccination.

\footnotetext{
${ }^{1}$ Faculdade de Direito de Vitória - FDV - Espírito Santo - Brasil
} 


\section{CONSIDERAÇÕES INICIAIS}

A pandemia do novo coronavírus, decretada pela Organização Mundial de Saúde - OMS no dia 11 de março de 2020, vem apresentando diversas consequências negativas para a sociedade, especialmente no que concerne à saúde e à vida dos cidadãos.

No Brasil, de acordo com os dados extraídos do Painel Coronavírus do governo federal (BRASIL, Ministério da Saúde, 2021), já foram confirmados mais de 422 mil óbitos pela Covid-19 e o número de contaminados, em maio de 2021, continua em níveis elevados.

Em vista desses fatos, os hospitais públicos e privados vêm se mostrando incapazes de atender satisfatoriamente a demanda por tratamento médico e de internações, sendo necessária a adoção, pelos governos estaduais e municipais, de medidas restritivas, como, por exemplo, a imposição do uso de máscaras, proibição de circulação em órgãos e locais públicos, e a restrição da abertura dos comércios locais.

A esperança, a curto prazo, é a aplicação de vacinas contra a Covid-19, que se constitui como único mecanismo viável para amenizar consideravelmente as consequências da pandemia, mormente pelo fato de que diversos testes científicos realizados, em nível mundial, vêm demonstrando a eficácia de imunização, mesmo que por tempo determinado.

A Lei Federal n.․ 13.979/2020 (BRASIL, 2020), que dispõe sobre as medidas de enfrentamento da emergência de saúde pública de importância internacional decorrente do coronavírus, em seu artigo 3ํㅡㄹ inciso III, alínea "d", estipula a possibilidade de determinar a realização compulsória de vacinação, bem como adotar outras medidas profiláticas relacionadas à Covid-19.

Contudo, é perceptível ${ }^{2}$ uma movimentação de determinados setores da sociedade no sentido contrário à vacinação contra a Covid-19, seja por motivo de crença religiosa ou por convicção política/filosófica, iniciando-se um debate acerca de sua (não) obrigatoriedade.

Visando o reconhecimento da (in)constitucionalidade do supramencionado dispositivo, foram ajuizadas duas ações direta de inconstitucionalidade junto ao Supremo Tribunal Federal (ADIs $\mathrm{n}$. 은 6.586 e 6.587), em que se discute que a realização compulsória de vacinação violaria os direitos à vida, à saúde, à liberdade individual, bem como o princípio da dignidade da pessoa humana (art. 5º, caput; art. 6으, caput; e art. 196, caput; todos da CRFB/88).

Alega-se, outrossim, que violaria o direito à intangibilidade, inviolabilidade e integridade do corpo humano, afigurando-se flagrantemente inconstitucional qualquer determinação legal, regulamentar ou administrativa no sentido de implementá-la de forma forçada e sem consentimento do indivíduo.

O presente artigo pretendeu realizar uma análise hermenêutica do ordenamento jurídico brasileiro, utilizando a perspectiva teórica do Grupo de Pesquisa "Hermenêutica jurídica e jurisdição constitucional" do Curso de Mestrado do Programa de Pós-Graduação da Faculdade de Direito de Vitória (FDV), em Direitos e Garantias Fundamentais, a fim de verificar se a decisão proferida pelo Supremo Tribunal Federal é adequada ao paradigma do Estado Democrático de Direito.

\footnotetext{
2 Nesse sentido, segue notícia veiculada na revista on-line da "Veja", em que narra o crescimento dos movimentos antivacinas no Brasil e no mundo. Disponível em: https://veja.abril.com.br/saude/covid-19-operigosissimo-crescimento-dos-movimentos-antivacina/
} 
Utilizou-se, para tanto, do método dialético diante da necessidade de realizar uma interpretação dinâmica da realidade (GIL, 2008, p. 14). Outrossim, a presente pesquisa teve como substrato metodológico a análise bibliográfica e documental, eis que foram analisados diversos doutrinadores e dispositivos constitucionais e infraconstitucionais do ordenamento jurídico brasileiro no tocante aos direitos e garantias constitucionais, em especial direitos à vida, à saúde, à liberdade individual, bem como o princípio da dignidade da pessoa humana.

Sob essa perspectiva, indaga-se o seguinte: é compatível com o Estado Democrático de Direito a imposição de sanções pela recusa de imunização pela vacinação?

\section{A VACINAÇÃO OBRIGATÓRIA E O ORDENAMENTO JURÍDICO BRASILEIRO}

A pandemia da Covid-19, apesar de sua atualidade, reacendeu o debate acerca da obrigatoriedade da vacinação no Brasil, que perdura desde meados do século XIX. Em 1837, para as crianças, e em 1846, para os adultos, a vacinação obrigatória já era regulamentada pelas autoridades públicas (AGÊNCIA FIOCRUZ DE NOTÍCIAS, 2005), mas não era exigida, uma vez que não era distribuída a todos de forma ampla.

Já no início do século XX, houve uma manifestação epidêmica de varíola no Brasil, de maneira especial no estado do Rio de Janeiro, onde a população presenciava o estado crítico das condições de higiene e saneamento básico, especialmente nas áreas mais carentes da cidade.

As autoridades públicas, preocupadas com a situação, procuravam alternativas para conter o avanço da doença no país, sendo que, em 8 de março de 1904, foi editado o Decreto n. ${ }^{0}$ 5.156, impondo restrições mais enérgicas no combate à varíola, como, por exemplo, a entrada forçada das autoridades sanitárias em residências (art. 993) e o recolhimento de pessoas acometidas pela doença em "edifício apropriado", onde deveriam ficar isoladas durante doze dias, sob suas custas (art. 2094).

Posteriormente, o então presidente da república, Francisco de Paula Rodrigues Alves, sob as orientações de Oswaldo Cruz, que exercia a função na Diretoria Geral de Saúde Pública (PORTO, 2003, p. 1) encaminhou ao Congresso Nacional um projeto de lei com objetivo de impor a obrigatoriedade de vacinação contra a varíola, bem como outras medidas restritivas de direito.

Nesse sentido, foi sancionada a Lei Federal n.. 1.261, em 31 de outubro de 1904, tornando obrigatória "em toda a Republica, a vaccinação e a revaccinação contra a varíola" (BRASIL, 1904).

3 Art. 99 do Decreto n. ${ }^{-5.156 / 1904}$. Nas visitas que a autoridade sanitaria fizer aos hoteis, casas de pensão, de commodos, hospedarias, albergues, avenidas, estalagens e outras habitações do mesmo genero, aos hospitaes casa de saude, maternidades, enfermarias particulares, asylos, pensões, collegios, escolas, theatros, casas de divertimentos, fabricas, officinas, etc., ser-lhe-ha facultada a entrada immediata, sempre que o exigir 0 interesse da saude publica.

4 Art. 209 do Decreto n.․ 5.156/1904. As pessôas que não quizerem acceitar as medidas prophylaticas constantes do artigo antecedente serão recolhidas, em observação, a um edificio apropriado, durante doze dias, correndo as despezas do estadia por conta das pessôas isoladas, pelas quaes ficará responsavel o chefe da familia ou quem suas vezes fizer, depositando este a somma correspondente á estadia das pessôas na casa de observação. 
De acordo com Porto (2003, p. 1), foi criada uma polícia sanitária com o poder de "desinfetar casas, caçar ratos e matar mosquitos. Com a imposição da vacinação obrigatória, as brigadas sanitárias entravam nas casas e vacinavam as pessoas à força".

Via de consequência, o governo federal viu aumentar o número de opositores, que alegavam que

[...] métodos de aplicação do decreto de vacinação eram truculentos, os soros e sobretudo os aplicadores pouco confiáveis e os funcionários, enfermeiros, fiscais e policiais encarregados da campanha manifestavam instintos brutais e moralidade discutível. (SEVCENKO, 1984, p. 7)

Há quem dizia, ainda, similarmente ao que ocorre atualmente com relação a vacina contra a Covid-195, que quem se vacinava "ficava com feições bovinas" (AGÊNCIA FIOCRUZ DE NOTíCIAS, 2015), uma vez que a vacina contra a varíola era proveniente da extração de líquidos de pústulas de vacas doentes.

Noutro giro, tais opositores da vacinação obrigatória contra a varíola também pugnavam pela liberdade de consciência de cada indivíduo, senão vejamos:

[...] que deixasse a cada consciência a liberdade de decidir pela sua aplicação ou não, podendo, inclusive, escolher as condições que melhor the conviessem para recebê-la. (SEVCENKO, 1984, p. 14)

Em face de toda essa problemática, eclodiu, entre os dias 10 e 16 de novembro de 1904, na cidade do Rio de Janeiro, diversos focos de manifestação contra as medidas adotadas pelo governo federal no combate à epidemia da varíola, chegando a ser conhecida como a "Revolta da Vacina".

De acordo com Porto (2003, p. 1)

Carroças e bondes foram tombados e incendiados, lojas saqueadas, postes de iluminação destruídos e apedrejados. Pelotões dispararam contra a multidão. Durante uma semana, as ruas do Rio viveram uma guerra civil. Segundo a polícia, o saldo negativo foi de 23 mortos e 67 feridos, tendo sido presas 945 pessoas, das quais quase a metade foi deportada para o Acre, onde foi submetida a trabalhos forçados.

Não se pode ignorar que se tratou de um movimento histórico de elevada importância, cujo papel fundamental foi exercido por Oswaldo $\mathrm{Cruz}^{6}$, que defendeu o controle da varíola por meio da vacina.

Apesar dos inúmeros percalços e do insucesso, à época, de se instituir a vacinação obrigatória, promoveu-se um amplo debate acerca de seus benefícios, culminando na

\footnotetext{
${ }^{5}$ O presidente da república, Jair Bolsonaro, em entrevista concedida em dezembro de 2020 , sugeriu que ao tomar a vacina contra a Covid-19 a pessoa poderia "virar jacaré". Disponível em: https://istoe.com.br/bolsonarosobre-vacina-de-pfizer-se-voce-virar-um-jacare-e-problema-de-voce/. Acesso em: 14 mai. 2021.

${ }^{6}$ Oswaldo Cruz foi condecorado com diversas medalhas de mérito pelo governo federal, sendo responsável pela reforma do Código Sanitário e a reestruturação dos órgãos de saúde e higiene no Brasil. Disponível em: https://portal.fiocruz.br/trajetoria-do-medico-dedicado-ciencia. Acesso em: 10 mai. 2021.
} 
institucionalização do Programa Nacional de Imunizações - PNI, em 1973, e na aprovação da Lei Federal n.ำ 6.259, em 1975.

Superadas as brevíssimas considerações históricas, é importante mencionar que o artigo $3^{\circ}$ da Lei Federal n. 6.259/1975 atribuiu ao Ministério da Saúde a função de elaborar o Plano Nacional de Imunização - PNI, de forma a definir as vacinações, inclusive as de caráter obrigatório. Atribui-se, outrossim, às autoridades estaduais e municipais as funções de execução do referido plano, a fim de viabilizar o seu cumprimento.

De forma a regulamentar a Lei Federal n.ำ 6.259/1975, foi também foi editado, em 1976, o Decreto $n . .78 .231$, que impõe ao Ministério da Saúde a atualização, bienal, do Programa Nacional de Imunizações, de maneira a definir e adequar o quadro nosológico a ser combatido de forma preventiva pela vacinação.

Filó e Ank (2021, p. 5), ao tecerem considerações acerca dos meios coercitivos do Programa Nacional de Imunizações - PNI, ressaltam que

[...] o meio utilizado para obrigar o uso foi, especialmente, a emissão de certificado obrigatório de vacinação, punição de advertência e multa e restrições de acesso a benefícios estatais. Além das normas persuasivas postas no regime não democrático, investiu-se também em propaganda, educação e estrutura para vacinação.

No mesmo sentido, em 1990, o Estatuto da Criança e do Adolescente (Lei Federal n.․ 8.069), em seu artigo 14, estabeleceu a vacinação obrigatória das crianças nos casos recomendados pelas autoridades sanitárias.

Vê-se, portanto, que mesmo após a promulgação da Constituição Federal de 1988, que fundou o paradigma do Estado Democrático de Direito, a vacinação obrigatória continuou a ser exigida, inclusive, como forma de garantir a proteção dos direitos fundamentais à saúde (art. 196, CRFB/1988) e da infância (art. 227, CRFB/1988).

Com o advento da pandemia do novo coronavírus em 2020, a questão da vacinação obrigatória foi colocada novamente em pauta, especialmente em face da Lei Federal n.ำ13.979/2020, que dispõe sobre as medidas para o enfrentamento da Covid-19.

Isto porque, em seu artigo $3^{\circ}$, inciso III, alínea "d", permite a adoção, pelas autoridades públicas, de medidas de determinação de realização compulsória de vacinação e outras medidas profiláticas.

Argumenta-se, dessa forma, pela inconstitucionalidade da aplicação de vacinas de forma compulsória e/ou obrigatória, especialmente em face da aprovação, em regime de urgência, das vacinas contra a Covid-19.

Alegam, outrossim, que não há comprovação científica cabal que garanta a imunização de forma segura, bem como relatam a ausência de estudos acerca dos efeitos colaterais eventualmente causados durantes os testes. 
Dessarte, com o objetivo de tornar definitiva a interpretação a ser dada ao dispositivo supramencionado, ou até mesmo o reconhecimento de sua inconstitucionalidade, o Supremo Tribunal Federal foi instado a se manifestar, conforme será tratado no capítulo seguinte.

\section{O ENTENDIMENTO DO SUPREMO TRIBUNAL FEDERAL NO JULGAMENTO DAS ADIs N.}

\subsection{6 e N. 6.587}

Conforme exposto anteriormente, foram ajuizadas duas ações diretas de inconstitucionalidade (ADIs n. 6.586 e 6.587) junto ao Supremo Tribunal Federal, colocando em discussão a (in)constitucionalidade do artigo 3oㅗㄹ inciso III, alínea "d", da Lei Federal n.ำ 13.979/2020.

A Ação Direta de Inconstitucionalidade n. 6.586 foi proposta pelo Partido Democrático Trabalhista - PDT, de forma a conferir interpretação conforme ao supramencionado dispositivo, a fim de que fosse estabelecida a competência dos Estados e Municípios para determinar a realização compulsória de vacinação e outras medidas profiláticas no combate à pandemia da Covid-19, de forma a retirar tal decisão da União, mais especificamente do Ministério da Saúde, uma vez que dava indícios ${ }^{7}$ de que não adotaria a política da vacinação obrigatória.

Alega-se, nesse sentido, que

[...] se a União, no exercício da competência concorrente, fixa parâmetros suficientemente protetivos em matéria de vacinação e outras medidas profiláticas, não pode o Estado-membro adotar a proteção deficiente. Contudo, omitindo-se a União em seu dever constitucional de proteção e prevenção pela imunização em massa, não pode ser vedado aos Estados a empreitada em sentido oposto, isto é, da maior proteção, desde que amparado em evidências científicas seguras. (BRASIL, Supremo Tribunal Federal, ADI 6586, p. 23, 2020)

Noutro giro, o Partido Trabalhista Brasileiro - PTB propôs a Ação Direta de Inconstitucionalidade $\mathrm{n} . \stackrel{0}{6.587}$, visando o reconhecimento da incompatibilidade do artigo $3^{\circ}$, inciso III, alínea "d", da Lei Federal n. 13.979/2020 com os direitos fundamentais à vida, à saúde e com o princípio da dignidade da pessoa humana.

A referida ação fundamenta-se sob o argumento de que não haveria, atualmente, estudos científicos que garantissem a plena segurança dos efeitos colaterais das vacinas, muito menos a certeza de sua eficácia no combate à Covid-19, especialmente em razão de serem antecipadas diversas etapas obrigatórias para averiguar a segurança da vacina.

O Partido Trabalhista Brasileiro - PTB, em sua inicial, afirma que a vacinação compulsória serviria, na verdade, para realizar um verdadeiro teste em massa na população brasileira, o que poderia vir a afetar a saúde de milhares e comprometer o próprio Sistema Único de Saúde - SUS.

\footnotetext{
${ }^{7}$ Nesse sentido, foi noticiado pela CNN Brasil a entrevista concedida pelo presidente da república. Disponível em: https://www.cnnbrasil.com.br/saude/2020/10/19/bolsonaro-vacina-nao-sera-obrigatoria-e-ponto-final. Acesso em: 14 mai. 2021.
} 
Outrossim, argumenta-se que a imposição da aplicação de vacina feriria a liberdade de escolha do indivíduo, devendo ser garantido àqueles que não se sentirem seguros a possibilidade de recusa à vacinação.

O Supremo Tribunal Federal (BRASIL, 2020), em 18 de dezembro de 2020, por maioria dos votos, julgou parcialmente procedente as referidas ações e fixou a seguinte tese de julgamento, ipsis litteris:

Ementa: AÇÕES DIRETAS DE INCONSTITUCIONALIDADE. VACINAÇÃO COMPULSÓRIA CONTRA A COVID-19 PREVISTA NA LEI 13.979/2020. PRETENSÃO DE ALCANÇAR A IMUNIDADE DE REBANHO. PROTEÇÃO DA COLETIVIDADE, EM ESPECIAL DOS MAIS VULNERÁVEIS. DIREITO SOCIAL À SAÚDE. PROIBIÇÃO DE VACINAÇÃO FORÇADA. EXIGÊNCIA DE PRÉVIO CONSENTIMENTO INFORMADO DO USUÁRIO. INTANGIBILIDADE DO CORPO HUMANO. PREVALÊNCIA DO PRINCÍPIO DA DIGNIDADE HUMANA. INVIOLABILIDADE DO DIREITO À VIDA, LIBERDADE, SEGURANÇA, PROPRIEDADE, INTIMIDADE E VIDA PRIVADA. VEDAÇÃO DA TORTURA E DO TRATAMENTO DESUMANO OU DEGRADANTE. COMPULSORIEDADE DA IMUNIZAÇÃO A SER ALÇANÇADA MEDIANTE RESTRIÇÕES INDIRETAS. NECESSIDADE DE OBSERVÂNCIA DE EVIDÊNCIAS CIENTÍFICAS E ANÁLISES DE INFORMAÇÕES ESTRATÉGICAS. EXIGÊNCIA DE COMPROVAÇÃO DA SEGURANÇA E EFICÁCIA DAS VACINAS. LIMITES À OBRIGATORIEDADE DA IMUNIZAÇÃO CONSISTENTES NA ESTRITA OBSERVÂNCIA DOS DIREITOS E GARANTIAS FUNDAMENTAIS. COMPETÊNCIA COMUM DA UNIÃO, ESTADOS, DISTRITO FEDERAL E MUNICÍPIOS PARA CUIDAR DA SAÚDE E ASSISTÊNCIA PÚBLICA. ADIS CONHECIDAS E JULGADAS PARCIALMENTE PROCEDENTES. I - A vacinação em massa da população constitui medida adotada pelas autoridades de saúde pública, com caráter preventivo, apta a reduzir a morbimortalidade de doenças infeciosas transmissíveis e a provocar imunidade de rebanho, com vistas a proteger toda a coletividade, em especial os mais vulneráveis. II - A obrigatoriedade da vacinação a que se refere a legislação sanitária brasileira não pode contemplar quaisquer medidas invasivas, aflitivas ou coativas, em decorrência direta do direito à intangibilidade, inviolabilidade e integridade do corpo humano, afigurandose flagrantemente inconstitucional toda determinação legal, regulamentar ou administrativa no sentido de implementar a vacinação sem o expresso consentimento informado das pessoas. III - A previsão de vacinação obrigatória, excluída a imposição de vacinação forçada, afigura-se legítima, desde que as medidas às quais se sujeitam os refratários observem os critérios constantes da própria Lei 13.979/2020, especificamente nos incisos I, II, e III do $\S 2^{\circ}$ do art. $3^{\circ}$, a saber, o direito à informação, à assistência familiar, ao tratamento gratuito e, ainda, ao "pleno respeito à dignidade, aos direitos humanos e às liberdades fundamentais das pessoas", bem como os princípios da razoabilidade e da proporcionalidade, de forma a não ameaçar a integridade física e moral dos recalcitrantes. IV - A competência do Ministério da Saúde para coordenar o Programa Nacional de Imunizações e definir as vacinas integrantes do calendário nacional de imunização não exclui a dos Estados, do Distrito Federal e dos Municípios para estabelecer medidas profiláticas e terapêuticas destinadas a enfrentar a pandemia decorrente do novo coronavírus, em âmbito regional ou local, no exercício do poder-dever de "cuidar da saúde e assistência pública" que Ihes é cometido pelo art. 23, II, da Constituição Federal. V - ADls conhecidas e julgadas parcialmente procedentes para conferir interpretação conforme à Constituição ao art. $3^{\circ}$, III, d, da Lei 13.979/2020, de maneira a estabelecer que: (A) a vacinação compulsória não significa vacinação forçada, por exigir sempre o consentimento do usuário, podendo, contudo, ser implementada 
por meio de medidas indiretas, as quais compreendem, dentre outras, a restrição ao exercício de certas atividades ou à frequência de determinados lugares, desde que previstas em lei, ou dela decorrentes, e (i) tenham como base evidências científicas e análises estratégicas pertinentes, (ii) venham acompanhadas de ampla informação sobre a eficácia, segurança e contraindicações dos imunizantes, (iii) respeitem a dignidade humana e os direitos fundamentais das pessoas; (iv) atendam aos critérios de razoabilidade e proporcionalidade, e (v) sejam as vacinas distribuídas universal e gratuitamente; e (B) tais medidas, com as limitações expostas, podem ser implementadas tanto pela União como pelos Estados, Distrito Federal e Municípios, respeitadas as respectivas esferas de competência.

Acórdãos no mesmo sentido

(ADI 6587 PROCESSO ELETRÔNICO JULG-17-12-2020 UF-DF TURMATP MIN-RICARDO LEWANDOWSKI N.PÁG-231 DJe-063 DIVULG 06-042021 PUBLIC 07-04-2021)

De forma inicial, verifica-se que o Supremo Tribunal Federal buscou ressaltar a importância da imunização para promoção da saúde de toda a coletividade, uma vez que é a única medida apta a garantir a redução do número de infectados e, via de consequência, números de óbitos.

Nesse sentido, buscou diferenciar o conceito da vacinação obrigatória da vacinação compulsória, eis que aquela não permite a adoção de medidas invasivas, que venham a ameaçar a intangibilidade do corpo humano.

Isso não traduz, de acordo com a decisão, a impossibilidade de adoção de medidas coercitivas indiretas, desde que sejam regulamentadas por lei, como vem sendo feito pela Lei Federal n.. 6.259/1975 e pelas demais normativas regulamentadoras emanadas pelo Ministério da Saúde.

Nessa esteira, a Corte Suprema entendeu que, para aplicação das medidas restritivas anteriormente citadas, é necessária a observância de determinados requisitos, ou seja, que a exigência da vacinação obrigatória tenha como base evidências científicas; venham acompanhadas de ampla informação acerca de sua eficácia, segurança e contraindicações; respeitem a dignidade da pessoa humana e os direitos fundamentais das pessoas; a observância dos critérios de razoabilidade e proporcionalidade; e que as vacinas sejam distribuídas universal e gratuitamente.

Outrossim, o Supremo Tribunal Federal fixou o entendimento de que a coordenação do Programa Nacional de Imunizações - PNI é atribuição do Ministério da Saúde, cabendo aos demais entes federados, concorrentemente, estipular as medidas profiláticas e terapêuticas necessárias ao combate à pandemia.

Dessarte, faz-se necessária a análise dos argumentos utilizados pela Corte Suprema, a fim de verificar sua adequação ao paradigma do Estado Democrático de Direito, especialmente com intuito de não se perpetuarem horrores como o ocorrido em 1904, quando o combate à varíola se tornou palco de manifestações sangrentas, mas também não deixar que argumentos políticos ou ideológicos possam prejudicar a adoção de medidas tão essenciais como a vacinação.

\section{ENTRE A LIBERDADE INDIVIDUAL E A SAÚDE PÚBLICA: A (IN)CONSTITUCIONALIDADE DA VACINAÇÃO OBRIGATÓRIA SOB A PERSPECTIVA DO PARADIGMA DO ESTADO DEMOCRÁTICO DE DIREITO}


Conforme explano anteriormente, o Supremo Tribunal Federal, no julgamento das ações direta de inconstitucionalidade n.ํㅜ 6.586 e 6.587, fixou o entendimento de que a vacinação obrigatória não significa vacinação forçada, eis que sempre exige o consentimento de seu usuário.

No entanto, a Corte Suprema entendeu cabível a imposição de medidas indiretas e coercitivas àqueles que se recusarem a vacinar, as quais compreendem, por exemplo, a restrição de certas atividades ou a frequência a determinados lugares.

Para que tais medidas sejam consideradas constitucionais, faz-se necessária a observância de determinados requisitos, a saber: i) a previsão legal; ii) que tenham como base evidências científicas e análises estratégicas pertinentes; iii) a ampla informação sobre eficácia, segurança e contraindicações dos imunizantes; iv) respeito à dignidade humana e aos direitos fundamentais das pessoas; v) o atendimento aos critérios de razoabilidade e proporcionalidade; vi) que as vacinas sejam distribuídas universal e gratuitamente.

De forma inicial, faz-se necessário analisar a presente decisão tomando como base o paradigma do Estado Democrático de Direito, o qual foi implementado pela Constituição Federal de 1988.

De acordo com Alexandre de Castro Coura e Renata Pereira Carvalho Costa (2010, p. 2425), o Estado Democrático de Direito representa

"[...] muito mais do que imprimir a necessidade de uma constituição como vinculação jurídica do poder, trouxe para o epicentro a pessoa humana e sua dignidade. Nesse sentido, a dignidade da pessoa humana passa a conformar um núcleo mínimo de onde emanam diretrizes para interpretação e aplicação dos direitos fundamentais. Ora, se os direitos fundamentais constituem um mínimo para a manutenção da dignidade humana, qualquer interpretação ou aplicação restritiva desses direitos não se amolda às exigências desse paradigma constitucional, sendo, portanto, ilegítima"'”.

Verifica-se, pois, que o paradigma do Estado Democrático de Direito busca introduzir a dignidade da pessoa humana como núcleo mínimo para interpretação e aplicação dos direitos fundamentais, devendo ser garantido, inclusive, a proteção de tais direitos como forma de promoção da própria dignidade humana.

E justamente sob essa perspectiva, o Supremo Tribunal Federal, tomando como base o princípio da dignidade da pessoa humana, descrito no artigo 1ำ, inciso III, da Constituição Federal, entende que se afigura flagrantemente inconstitucional toda determinação legal, regulamentar ou administrativa no sentido de implementar a vacinação forçada das pessoas.

O ministro Ricardo Lewandoski, em seu voto nas ADIN n.ㅇ 6586 e 6587 (BRASIL, Supremo Tribunal Federal, 2020), afirmou o seguinte:

"[...] não pairam dúvidas acerca do alcance de duas garantias essenciais asseguradas às pessoas: a intangibilidade do corpo humano e a inviolabilidade do domicílio. Tais franquias, bem sopesadas, por si sós, já excluem, completamente, a possibilidade de alguém possa ser compelido a tomar uma vacina à força, contra sua vontade". 
Conforme dito alhures, essa diferenciação busca promover a reparação do ocorrido durante a "Revolta da Vacina" no ano de 1904, onde a própria legislação permitia a entrada forçada de agentes sanitários para promover a vacinação de pessoas.

Não obstante, também era permitido o recolhimento forçado de pessoas acometidas pela varíola, que, inclusive, arcavam com suas próprias despesas durante a estadia em "edifício apropriado" indicado pelo governo federal.

Contudo, ainda que o indivíduo não possa vir a ser forçado a se vacinar, é possível, sob a perspectiva do Estado Democrático de Direito, que sejam impostas certas medidas coercitivas, conforme estabelecido na supramencionada decisão do Supremo Tribunal Federal.

A Constituição Federal de 1988, em seu título II, descreve os direitos e garantias fundamentais, onde constam, de forma especial, o direito à vida, à saúde, à liberdade individual, assim como o princípio da dignidade da pessoa humana. Tais princípios devem, indubitavelmente, ser resguardados e protegidos contra ingerências de toda ordem.

Sob a ótica do paradigma do Estado Democrático de Direito, Adolfo (2008, p. 98) aduz que a dignidade da pessoa humana é um verdadeiro valor-fonte da Constituição Federal de 1988, epicentro do sistema jurídico brasileiro.

Porém, apesar de vitais em um Estado Democrático de Direito, esses direitos e garantias fundamentais não são absolutos, mas, sim, utilizados como mandamentos de otimização e devendo ser cumpridos no grau máximo de sua efetividade (NUNES JUNIOR, 2018, p. 237).

Reforçando essa ideia, Bedê Junior e Rezende (2020, p. 109) aduzem que é necessário "entender que nenhum direito fundamental é de todo absoluto, podendo ser restringido em determinados casos, especialmente quando ficar constatado o seu abuso".

Conforme bem explicam Borges, Cervi e Piaia (2020, p. 147), o novo coronavírus alcançou o status de pandemia e vem causando o colapso dos sistemas de saúde, inclusive, de diversos países desenvolvidos, senão vejamos:

O novo coronavírus, causador da doença respiratória COVID-19 e oriundo da mutação do vírus corona, teve os primeiros casos registrados na província de Wuhan, República Popular da China, região habitada por aproximadamente 11 milhões de pessoas, e de lá, propagando-se para outros países, a doença alcançou status de pandemia pondo em crise sistemas de saúde eficientes como o da Itália, Espanha e Estados Unidos $[\ldots] "$.

Não diferente, no Brasil, as políticas e medidas sanitárias adotadas pelas autoridades públicas vem se mostrando ineficazes, sendo que a demanda por atendimento nos hospitais e pronto atendimentos públicos e privados aumenta diariamente, estando próximo ao próprio colapso do sistema de saúde.

A título de ilustração, verifica-se que, em 10 de maio de 2021, o Brasil já registrou mais de 422 mil óbito pela Covid-19 (BRASIL, Ministério da Saúde, 2021), sendo que, entre os dias 9 de março de 2021 à 25 de abril de 2021, o país teve a maior média diária de mortes por Covid-19 no mundo. (SAMPAIO; Portal G1, 2021). 
A adoção de medidas enérgicas torna-se necessária, especialmente em face da aprovação seja em caráter emergencial ou definitivo, pela Agência Nacional de Vigilância Sanitária - Anvisa, das vacinas "Coronavac", "ChAdOx1 nCoV-19 (Vacina de Oxford)", e "mRNA BNT162 (Pfizer/BioNTech)", que demonstram ter sua eficácia comprovada por estudos científicos internacionais.

Evidentemente que a observância dos direitos e garantias fundamentais do indivíduo deve ser resguardada, mas a liberdade de escolha, o direito fundamental à livre convicção filosófica e política do indivíduo esbarra no próprio direito à saúde.

No que se refere ao direito fundamental à saúde, descrito no artigo 196 da Constituição Federal de 1988, Resende e Alves (2020, p. 131) aduzem o seguinte:

"[...] não se pode negar que o direito fundamental à saúde é dotado de uma dimensão positiva (prestacional) e outra negativa (defensiva, de não intervenção), sendo que esta exige do Estado o respeito e a não ingerência na saúde do indivíduo".

Nesse sentido, verifica-se que o direito fundamental à saúde compreende sua dimensão positiva e negativa. A dimensão negativa impõe a não ingerência na saúde do indivíduo, nos termos da decisão proferida pelo Supremo Tribunal Federal, que fixou o entendimento de que não é possível a vacinação forçada.

Noutro giro, a dimensão positiva, de caráter prestacional, é a que cabe ao Estado prestar um serviço público de forma universal e gratuito, implementando políticas sociais e econômicas que "visem à redução do risco de doença e de outros agravos e ao acesso universal e igualitário às ações e serviços para sua promoção, proteção e recuperação", conforme caput do artigo 196 da Constituição Federal (BRASIL, 1988).

Inclusive, nos termos das lições de Alencar e Lozada (2017, p. 31), o "direito à saúde deve sair do plano retórico para ocupar seu devido lugar de garantia constitucional que integra o conteúdo da dignidade humana". Nesse sentido, a promoção da saúde pública significa a própria promoção da dignidade humana, que é núcleo essencial do próprio paradigma do Estado Democrático de Direito.

Indaga-se, entretanto, de que forma o Estado pode vir a garantir tais políticas sociais, visando à redução do risco de doença e de outros agravos, se a própria população não se propõe a cooperar para garantir a chamada imunização de rebanho?

Visando encontrar meios alternativos que não venham a afrontar o princípio da dignidade da pessoa humana, em especial a intangibilidade do corpo do indivíduo, no Brasil, foi editada a Lei Federal n. 6.259/1975, que dispõe sobre o Programa Nacional de Imunizações, estipulando limitações de direitos àqueles que se recusam a apresentar o atestado de vacinação.

Essa discussão se intensificou com a edição da lei federal n. 0 13.979/2020, que dispõe sobre as medidas para enfrentamento da emergência de saúde pública decorrente do coronavírus (SarsCov-2), que estipula em seu artigo $3^{\circ}$, inciso III, alínea "d", a determinação de realização compulsória de vacinação e outras medidas profiláticas no combate a pandemia.

\footnotetext{
8 É possível conferir o andamento da aprovação das vacinas pelo link disponível em: https://www.gov.br/anvisa/pt-br/assuntos/paf/coronavirus. Acesso em: 14 mai. 2021.
} 
Nesse sentido, verifica-se acertada a decisão proferida pelo Supremo Tribunal Federal no julgamento das $A D I$ n. 05.856 e 5.857, uma vez que o estabelecimento dessas medidas busca promover o próprio direito à vida das pessoas, especialmente diante do elevado número de óbitos presenciado no Brasil.

Não obstante, tais medidas tornam-se necessárias com intuito de evitar que discussões políticas, tais quais presenciadas atualmente, possam vir a influir na adoção de medidas básicas para promoção da imunização dos cidadãos.

Outra forma que também pode vir a ser utilizada pelas autoridades públicas, de forma especial pelo Poder Legislativo e pelo Poder Executivo, é implementar não somente medidas coercitivas, mas também medidas de incentivo, como vem ocorrendo (com sucesso) nos Estados Unidos da América9.

Tais medidas podem servir até mesmo para incentivar determinados ramos empresariais que tiveram os negócios prejudicados durante a pandemia, como, por exemplo, a redução (mesmo que mínima) do Imposto sobre os Produtos Industrializados - IPI de veículos automotores ou até mesmo descontos de meia-entrada em eventos sociais, quando o "novo normal" se estabelecer.

Outrossim, a concessão de dia de folga para empregados vacinados, tal como ocorre com aqueles que doam sangue, bem como o parcelamento de débitos tributários sem aplicação de multas. Todas essas formas podem vir a ser essenciais no combate à pandemia e, por lógico, se adequam ao paradigma do Estado Democrático de Direito.

\section{CONSIDERAÇÕES FINAIS}

A pandemia da Covid-19, certamente, promoveu e promoverá mudanças na sociedade que perdurarão por muitos anos. As suas consequências afetam desde a economia até a maneira de se pensar o próprio Direito.

O Supremo Tribunal Federal, como órgão responsável pelo estrito cumprimento dos ditames constitucionais, foi instado a se manifestar mais uma vez a respeito da questão da vacinação obrigatória.

A decisão proferida no julgamento das ações direta de inconstitucionalidade n. 5.856 e 5.857 foi exemplar ao diferenciar a vacinação forçada da vacinação obrigatória. De forma a não repetir os erros do passado, como ocorreu durante a "Revolta da Vacina" em 1904, a Suprema Corte fez questão de vedar, com fulcro na própria dignidade da pessoa humana, a possibilidade de um indivíduo ser forçado a vacinar.

Todavia, averiguou a constitucionalidade da aplicação de medidas indiretas que visam garantir a vacinação obrigatória da população brasileira. Isto porque constitui medida apta a promover

\footnotetext{
${ }^{9}$ As autoridades públicas dos EUA vêm adotando diversas medidas de incentivo à vacinação, que vão desde a concessão de desconto de meia-entrada em eventos até o fornecimento de cervejas e incentivos pecuniários. Disponível em: https://www.correiobraziliense.com.br/mundo/2021/05/4923111-estimulo-a-vacinacao-nos-euaoferece-ingressos-cerveja-maconha-e-dinheiro.html. Acesso em: 14 mai. 2021.
} 
a própria saúde da coletividade, uma vez que a própria Agência Nacional de Vigilância Sanitária ANVISA, ao aprovar determinadas vacinas, atestou pela sua eficácia e segurança.

Tais medidas, além da observância dos diversos outros requisitos, como, por exemplo, a ampla informação acerca da eficácia, segurança e contraindicações de determinada vacina, promovem o aumento de segurança e credibilidade para que as pessoas venham a se vacinar de forma voluntária.

Para aquelas que, seja por motivo político, religioso ou ideológico, são contra a vacinação, é possível que, sob a ótica do paradigma do Estado Democrático de Direito, seja aplicadas determinadas sanções que venham, inclusive, a cercear o próprio exercício de sua cidadania.

Ora, conforme todo o exposto no presente estudo, o exercício da cidadania passa pela própria concepção de saúde pública, uma vez que a Covid-19 pressupõe a adoção de diversas medidas sanitárias que vão do distanciamento social ao uso da vacina.

Defende-se, outrossim, a utilização de mecanismos incentivadores à vacinação em massa, uma vez que podem servir de reforço para aumentar o índice de imunizados, além de promover o estímulo ao crescimento econômico de setores prejudicados durante a pandemia.

Tais medidas, se corretamente aplicadas, podem vir a promover uma maior aceitação da vacina no seio social, além de serem, indubitavelmente, consonantes com o paradigma do Estado Democrático de Direito.

\section{REFERÊNCIAS}


ADOLFO, Luiz Gonzaga Silva. Dignidade da pessoa humana (ainda!) e Direito Civil: rápidas notas sobre um caminho por construir. Revista do Curso de Direito da FSG, ano 2, n. 4, jul./dez., p. $97-104,2008$

AGÊNCIA FIOCRUZ DE NOTÍCIAS. A Revolta da Vacina. 2005. Disponível em: <https://portal.fiocruz.br/noticia/revolta-da-vacina-2>. Acesso em: 10 mai. 2021.

ALENCAR, Rosmar Antonni Rodrigues Cavalcanti de; LOZADA, Claudia de Oliveira. Breve análise dos aspectos processuais que envolvem questões relacionadas à judicialização da saúde: a tutela antecipada. Revista do Direito, Santa Cruz do Sul, v. 2, n. 52, out. 2017. ISSN 1982-9957. Disponível em: <https://online.unisc.br/seer/index.php/direito/article/view/8738>. Acesso em 13. mai. 2021. DOI:http://dx.doi.org/10.17058/rdunisc.v2i52.8738.

BORGES, G. S.; CERVI, T. D.; PIAIA, T. C. O informacionalismo como uma ameaça ao direito humano à saúde em tempos de pandemia: as aporias da Covid-19 e os desafios da comunicação humana. Revista de Direitos e Garantias Fundamentais, v. 21, n. 1, p. 139-166, 24 nov. 2020.

BRASIL. Constituição da República Federativa do Brasil. Brasília, DF: Senado, 1988. Disponível em: <http://www.planalto.gov.br/ccivil_03/constituicao/ConstituicaoCompilado.htm>. Acesso em: 07 de jan. 2021.

BRASIL. Decreto n. 5.156. Dá novo regulamento aos serviços sanitarios a cargo da União. Brasília, DF: Presidência da República, 1904. Disponível em: < https://www2.camara.leg.br/legin/fed/decret/1900-1909/decreto-5156-8-marco-1904-517631 publicacaooriginal-1-pe.html>. Acesso em: 14 de mai. 2021.

BRASIL. Decreto n. ${ }^{\circ} 78.231$. Regulamenta a Lei $n^{\circ}$ 6.259, de 30 de outubro de 1975, que dispõe sobre a organização das ações de Vigilância Epidemiológica, sobre o Programa Nacional de Imunizações, estabelece normas relativas à notificação compulsória de doenças, e dá outras providências. Brasília, DF: Presidência da República, 1976. Disponível em: < https://www2.camara.leg.br/legin/fed/decret/1970-1979/decreto-78231-12-agosto-1976-427054norma-pe.html>. Acesso em: 14 de mai. 2021.

BRASIL. Lei $n^{\circ} 1.261$, de 31 de outubro de 1904. Torna obrigatorias, em toda a Republica, a vaccinação e a revaccinação contra a varíola. Disponível em: < https://www2.camara.leg.br/legin/fed/lei/1900-1909/lei-1261-31-outubro-1904-584180publicacaooriginal-106938pl.html\#: :text=Torna\%20obrigatorias\%2C\%20em\%20toda\%20a,dos\%20Estados\%20Unidos\%20do 
\%20Brazil\%3A\&text=1\%C2\%BA\%20A\%20vaccina\%C3\%A7\%C3\%A30\%20e\%20revaccina\%C3\%A7 \%C3\%A3o,obrigatorias\%20em\%20toda\%20a\%20Republica.>. Acesso em: 14 de mai. 2021.

BRASIL. Lei ํㅗ 8.069, de 13 de julho de 1990. Dispõe sobre o Estatuto da Criança e do Adolescente e dá outras providências. Disponível em: < http://www.planalto.gov.br/ccivil_03/leis/L8069compilado.htm>. Acesso em: 14 de mai. 2021.

BRASIL. Lei no 6.259 , de 30 de outubro de 1975. Dispõe sobre a organização das ações de Vigilância Epidemiológica, sobre o Programa Nacional de Imunizações, estabelece normas relativas à notificação compulsória de doenças, e dá outras providências. Disponível em: <http://www.planalto.gov.br/ccivil_03/leis/6259.htm>. Acesso em: 07 de jan. 2021.

BRASIL. Lei ํㅜ 13.979, de 06 de fevereiro de 2020. Dispõe sobre as medidas para enfrentamento da emergência de saúde pública de importância internacional decorrente do coronavírus responsável pelo surto de 2019. Disponível em: <http://www.planalto.gov.br/ccivil_03/_ato20192022/2020/lei/L13979compilado.htm>. Acesso em: 07 de jan. 2021.

BRASIL. Ministério da Saúde, 2021. Painel Coronavírus. Disponível em: $<$ https://covid.saude.gov.br/>. Acesso em: 14 de mai. 2021.

BRASIL, Supremo Tribunal Federal. ADI 6586, Rel. Min. Ricardo Lewandowski, Tribunal Pleno, julgado em 18/12/2020. Disponível em: $<$ http://portal.stf.jus.br/processos/detalhe.asp?incidente=6033038>. Acesso em: 07 jan. 2021.

BRASIL, Supremo Tribunal Federal. ADI 6587, Rel. Min. Ricardo Lewandowski, Tribunal Pleno, julgado em 18/12/2020. Disponível em: http://portal.stf.jus.br/processos/detalhe.asp?incidente=6034076>. Acesso em: 07 jan. 2021.

COSTA, Renata Pereira Carvalho; COURA, Alexandre de Castro. A atuação do magistrado e sua conformação paradigmática: o desafio de materializar o Estado Democrático de Direito, DPU, n. 32, p. 23-41, mar.-abril, 2010.

FILÓ, Maurício da Cunha Savino. ANK, Jaine Gláucia Teixeira. A vacinação compulsória contra o SARS-COV-2 como instrumento concretizador do direito à saúde. Revista Culturas Jurídicas. Vol. 8 , p. 1-25, 2021

FREIRE JÚNIOR, Américo Bedê; REZENDE, Eduardo Domingues. A (im)possibilidade de acesso a provas obtidas em aplicativo de mensagens instantâneas sem autorização judicial. Revista Magister de Direito Penal e Processual Penal, v. 96, p. 98-111, 2020. 
GIL, Antônio Carlos. Métodos e técnicas de pesquisa social. 6. ed. São Paulo: Atlas, 2008.

NUNES JUNIOR, Flávio Martins Alves. Curso de direito constitucional. $2^{\mathrm{a}}$ edição - São Paulo: Thomson Reuters Brasil, 2018.

PORTO, Mayla Yara. Uma revolta popular contra a vacinação. Cienc. Cult. [online]. 2003, vol.55, n.1, pp.53-54. ISSN 0009-6725.

PRODANOV, Cleber Cristiano. Metodologia do trabalho científico [recurso eletrônico]: métodos e técnicas da pesquisa e do trabalho acadêmico / Cleber Cristiano Prodanov, Ernani Cesar de Freitas. - 2. ed. - Novo Hamburgo: Feevale, 2013.

RESENDE, José Renato Venâncio; ALVES, Cândice Lisbôa. A vacinação obrigatória como um dever jurídico decorrente do direito fundamental à saúde. Revista da Faculdade de Direito UFPR, Curitiba, v. 65, n. 2, p. 129-148, maio/ago. 2020.

SAMPAIO, Lucas. Portal G1. Ranking da Covid: como o Brasil se compara a outros países em mortes, casos e vacinas aplicadas, 2021. Disponível em: < https://g1.globo.com/mundo/noticia/2021/04/29/ranking-da-covid-como-o-brasil-se-compara-a-outrospaises-em-mortes-casos-e-vacinas-aplicadas.ghtml>. Acesso em: 14 mai. 2021.

SEVCENKO, Nicolau. A revolta da vacina - mentes insanas em corpos rebeldes. São Paulo: Brasiliense, 1984 